\title{
EXTRAGONADAL GERM-CELL TUMORS - A REVIEW OF THE PATHOGENESIS, HISTOPATHOLOGICAL FINDINGS, DIAGNOSIS AND TREATMENT
}

\author{
Lucian IORGA ${ }^{1}$, Dragos MARCU ${ }^{1,2}$, Ovidiu BRATU ${ }^{1,2,3 凶}$, Bogdan SOCEA ${ }^{2}$, Tiberiu P. NEAGU², \\ Simona BUNGAU ${ }^{4}$, Ana Maria A. STANESCU², Camelia C. DIACONU ${ }^{2,5}$, Dan MISCHIANU ${ }^{1,2,3}$ \\ ${ }^{1}$ University Emergency Central Military Hospital, Bucharest, Romania \\ ${ }^{2}$ University of Medicine and Pharmacy „Carol Davila“, Bucharest, Romania \\ ${ }^{3}$ Academy of Romanian Scientists, Bucharest, Romania \\ ${ }^{4}$ University of Medicine and Pharmacy, Oradea, Romania \\ ${ }^{5}$ Clinical Emergency Hospital of Bucharest, Bucharest, Romania
}

Received 02 Oct 2019, Accepted 10 Nov 2019

https://doi.org/10.31688/ABMU.2019.54.4.16

\section{Abstract}

Primary extragonadal germ-cell tumors (EGCTs) are a rare group of neoplasms, that can exist anywere along the midline of the body, without the evidence of a primary gonadal tumor. Their morphology varies widely and includes teratoma, seminoma, yolk sac tumor, embryonal carcinoma, choriocarcinoma, and mixed GCTs. The ethiopathogenesis of EGCT is poorly understood, existing multiple theories. Diagnosis is often difficult, but an accurate one should be made in order to apply a correct management.

Keywords: extragonadal germ-cell tumors, pathogenesis, histhopathology, diagnosis, treatment.

\footnotetext{
Abbreviations

GCT - germ cell tumor

EGCT - extragonadal germ cell tumor

ST - seminomatous

NST - non seminomatous tumors

EC - embryonic carcinoma
}

\section{Résumé}

Tumeurs de cellules germinales extragonadiques pathogenèse, résultats histopathologiques, diagnostic et traitement

Les tumeurs germinales extragonadiques primaires (EGCT) constituent un groupe rare de néoplasmes pouvant exister n'importe où le long de la ligne médiane du corps, sans preuve d'une tumeur gonadique primaire. Leur morphologie varie considérablement et comprend les tératomes, les séminomes, les tumeurs du sac vitellin, les carcinomes embryonnaires, les choriocarcinomes et les GCT mixtes. L'éthiopathogenèse de l'EGCT est faiblement comprise, existant de multiples théories. Le diagnostic est souvent difficile, mais un diagnostic précis doit être fait afin d'appliquer une approche correcte

Mots-clés: tumeurs germinales extragonadiques, pathogenèse, histopathologie, diagnostic, traitement. 
YST - yolk sack tumor

FNAC - fine needle aspiration cytology

AFP - alfa-feto protein

beta-hCG - beta-human chorionic gonadotropin

LDH - lactate dehydrogenase

VIP - etoposide, ifosfamide, and cisplatin chemother-

apy

BEP - bleomycin, etoposide, and cisplatin chemother-

apy

RT - radiation therapy

PET - positron emission tomography

\section{INTRODUCTION}

Primary extragonadal germ-cell tumors (EGCT) are a rare group of neoplasms, representing $1-3 \%$ of all germ-cell tumors, that can be found in almost every structure along the midline of the body, from the brain to the coccyx, without evidence of gonadal primary tumors. The most common sites in which EGCT can be found include the mediastinum and retroperitoneum, with the brain closely behind ${ }^{1}$. The pineal gland and the sacrococcygeal area are less frequently encountered as anatomical locations for EGCT $^{2,3}$. However, there have been described isolated cases in the bladder, prostate, seminal vesicle, vulva, placenta, uterus and kidney ${ }^{4-9}$. It has been observed that females are less affected than males, with a higher incidence in white males (56.3/1 million) ${ }^{1}$.

EGCT are classified as seminomatous tumors (seminoma) and non-seminomatous tumors (teratoma, embryonal carcinoma, yolk-sac tumors and choriocarcinoma). Tumors that are constituted by two or more histological types are known as mixed germ cell tumors and are treated as NST.

Tumor type and location varies with age. Therefore, teratoma is the most frequent EGCT encountered in prepuberal patients, regardless of gender. In the same category of patients, the most common anatomical locations in which EGCTs resides are, in no particular order, the sacrococcygeal area, intracranial, mediastinum, head and neck and peritoneum. Teratoma, in prepuberal age, can be observed as pure or mixed tumor, frequently associated with yolk sac tumors $(\mathrm{YST})^{10,11}$.

In adults, teratoma is by far the most common histological type of EGCT encountered in females (90\%). Teratoma, seminoma, YST and mixed tumors are quite equally represented in males ${ }^{12}$.

Unlike testicular germ-cell tumors (GCTs), where there is no clear prognostic distinction between mature and immature teratoma, mature teratomas of the mediastinum generally behave in a benign manner. In adults, immature teratomas of the mediastinum can be aggressive tumors, similar to other non-seminomas, and have a poor prognosis, whereas in prepubertal children, immature elements in a teratoma are not associated with malignant behavior ${ }^{13,14}$.

\section{Pathogenesis}

The pathogenesis of EGCT is not clearly defined, so in the literature multiple theories exist. A first theory suggests that EGCTs are derived from primordial germ cells that fail to complete the normal migration along the urogenital ridge to the primordial gonads during embryonal development, most probably due to an anomaly in its microenvironment or to a cell defect ${ }^{15}$. Another theory, supported by McKenney et al, proposes as an etiopathogenetic mechanism the metastases developed from an undiagnosed or regressed („burned-out") primary germ-cell tumor in the gonads ${ }^{14}$. The probability of certain grades of regression has been studied in the literature and furthermore, EGCTs are more aggresive than GCT occuring in the gonads, as expected from metastatic disease.

A third theory involves genetic alterations. It has been observed that aneuploidy and chromosome 12 abnormalities are the most common genetic alterations observed in postpuberal GCTs. It has been demonstrated that in up to $96 \%$ of mediastinal seminoma exists an overexpression of $12 \mathrm{p}^{16}$. However, regarding genetic implication in the pathogenesis of non seminomatous tumors (NST) there are limited data available in the literature. Hasle et al observed that EGCT have a higher incidence in patients with genetic syndromes such as Klinefelter, Down and Li-Fraumeni ${ }^{17}$. Patients with Klinefelter syndrome tend to develop EGCT, especially located in the mediastinum. In a report from the Children's Oncology Group, approximately one third of patients with mediastinal GCTs had Klinefelter syndrome and the risk of developing a GCT among males with Klinefelter syndrome was estimated to be 1:4000. Williams et al concluded that males with mediastinal GCTs should be screened for Klinefelter syndrome ${ }^{18,19}$. 


\section{Histopathological findings}

EGCTs have the same morphological and immunohistochemical findings as their gonadal counterparts. Seminoma is characterized macroscopically by a lobular architecture, with a silvery cut surface and having up to $20 \mathrm{~cm}$ in size ${ }^{20}$. Microscopically, the tumor consists of large cells with gently eosinophilic cytoplasm, with a smooth nucleus and a prominent nucleolus.

EC is usually a large mass at the time of diagnosis, with necrosis and hemorrhage on the cut surface and with signs of invasion in the surrounding tissues. Microscopically, coagulative necrosis, „epithelial“ arrangements and nuclear atypia are useful for differential diagnosis with seminoma.

Teratoma is an encapsulated mass, sometimes lobulated, which presents on the cut surfaces a large pallet of tissues, cystic areas of mucinous, gelatinous or serous material. Occasionally, bone and teeth can be present. Looking at it through the microscope you can see several tissues with various degrees of maturation, arranged in a disorganized distribution.

Choriocarcinoma is seen as an infiltrating mass into the adjacent tissues, usually very hemorrhagic, being characterized microscopically by the presence of syncytiotrophoblastic and cytotrophoblastic cells.

The specimens for histopathological diagnosis can be acquired through incisional biopsies or Fine Needle Aspiration Cytology ultrasound or CT-guided. Seminoma usually presents a homomorphous and dissociated cell population, mononucleated, with large vesicular nuclei, prominent nucleoli and chromatin clumping and few loose small clusters on FNAC smears. Non seminomatous tumors (NST) are characterized by variegated morphological aspects on fine needle aspiration cytology (FNAC) smears. Therefore, YST is identified by cohesive clusters or acinar structures constituted of cells with vacuolated cytoplasm and large nuclei. Giant multinucleated tumor cells usually describe a choriocarcinoma. The cytopathology of embryonal carcinoma (EC) consists of necrosis and hemorrhagic areas, multiple anaplastic cells, hyperchromatic nuclei, basophilic cytoplasm arranged in glandular or papillary structures. The diagnosis of teratoma could be suspected when squamous cells, columnar cells and mesenchymal portions are observed ${ }^{21}$.

Regarding the immunohistochemical markers, the most important for seminoma are PLAP, POU5F1(OCT4), NANOG, SOX2, REX1, UTF1, KIT (CD117) or LIN28. These are the same as the factors of pluripotency regulation expressed by pluripotent germ cells tumors and normal gonocytes ${ }^{22-25}$. CD30 and SOX2 are specific immunohistochemical markers for $\mathrm{EC}^{26}$. Alpha fetoprotein, Glypican-3, Villin, SALL4 and LIN28, usually present on the surface of human yolk sac and early endoderm cells, are characteristic markers for YST. Recently, ZBTB16 (Zinc finger and BTB domain-containing protein 16) has been found to be more specific for YST, being expressed in up to $91.6 \%$ of extragonadal and metastatic YST ${ }^{27,28}$. $\beta$-hCG is highly specific for choriocarcinoma, which also expresses Glypican-3 and SALL4 ${ }^{29}$. Teratoma, usually, does not require immunohistochemical markers for the diagnosis.

\section{Diagnosis}

Suspicion of EGCTs is based on clinical diagnosis and imaging studies, but its diagnosis is confirmed by the histopathological findings from incisional biopsies or FNAC smears.

In establishing the diagnosis of EGCT it is important to exclude two possible pathologies: metastasis from a primary gonadal GCT and another type of poorly differentiated cancer. Therefore, testicular ultrasound should be performed in all patients with, as testicular palpation alone is not sufficient for exclusion of a primary gonadal GCT ${ }^{30}$. Another important element for differentiation between a primary EGCT and a metastasis from a gonadal GCT is that primary mediastinal GCTs occur in the anterior mediastinum, whereas testicular GCTs rarely metastasize to the anterior mediastinum. EGCTs can be distinguished from other poorly differentiated cancers only by histopathological evaluation.

Another important element in the diagnosis of EGCTs is the measurement of specific biochemical serum tumor markers, such as serum alfa-feto protein (AFP), beta-human chorionic gonadotropin (beta-hCG) and lactate dehydrogenase (LDH). These serum markers, not only are invaluable for diagnosis, but very helpful in the follow-up process. AFP is usually increased in non seminomatous EGGCTs while it is never increased in pure seminoma patients ${ }^{31}$. Frequently, pure YST, or mixed GCT containing YST cells presents elevated levels of AFP. Serum beta-hCG may be increased in pure seminoma, and non seminomatous GCTs. Serum LDH, the less specific serum marker, increases in $40 \%-60 \%$ of EGCTs patients, regardless of the histological type. In all these situations, it has been observed that the level of serum markers is proportionally higher according to the disease stage ${ }^{21,31}$.

\section{Mediastinal germ-cell tumors}

Teratoma of the mediastinum can exists in two forms: mature and immature. Mature mediastinal teratomas of the males, in contrast to the testicular teratoma, which is considered to have metastatic potential, are treated as benign tumors. It tends to grow slowly, being for the most part asymptomatic, 
therefore, it is usually diagnosed incidentally. If symptoms do appear, they are usually a result of compression and obstruction of surrounding organs. Manifestations could include: chest pain, cough, dyspnea, and bronchial obstruction and postobstructive pneumonia. There have been reported errosions into the bronchia, the pericardium, adjacent major blood vessels, or through the skin and are considered serious complications. Trichoptysis, or the expectoration of hair, can be rarely seen when a bronchial fistula is formed ${ }^{32-35}$. Immature teratoma are rarely seen.

Testicular seminoma rarely metastasizes to the medistinum in the absence of retroperitoneal lymph node involvement ${ }^{30}$. Primary mediastinal seminoma is a slow-growing mass and can reach impressive dimensions at the time of diagnosis. Due to the fact that it grows slowly, it is usually asymptomatic. Common complaints of patients include: chest pain, dyspnea, cough, weight loss, superior vena cava syndrome, fever, nausea. Beta-hCG is elevated in approximately one third of patients ${ }^{36}$.

An important fact for diagnosis and treatment is that if a tumor consist of a mixture of seminoma and teratoma it is considered a NST and treated as one. It has been observed that regarding mediastinal NST, YSTs are the most common subtypes. In one study on 64 cases, $60 \%$ were pure YST, $12 \%$ were pure choriocarcinomas, and $9 \%$ were pure embryonal carcinomas. Medistinal NST have a poor prognosis, with an overall survival rate at 5 years of only $45 \%$ 36,37. Unlike seminomatous GCT cases, NST patients are symptomatic and may complain of fever, chills, weight loss, chest pain, dyspnea, and/or superior vena cava syndrome. Sometimes, patients can present gynecomastia, when a choriocarcinoma that secrests high amount of beta-HCG is present ${ }^{35}$.

\section{Retroperitoneal germ-cell tumors}

Due to the inaccessibility of the region, these tumors usually grow silent and are frequently bulky at the time of diagnosis. If the tumor is large in scale, patients usually present with abdominal swelling and pain, early satiety, abdominal discomfort, most having a palpable abdominal mass. Pain can be located in the lumbar, inguinal or gluteal region and varies in intensity and severity. General symptoms such as asthenia, anorexia, weight loss or prolonged fever may be present. Signs of venous compression such as edema, varicocele, ascites and genital swelling can be present. In this region pure teratomas are rare.

In all cases a computed tomography should be performed to better characterize the tumor and its relationship with adjacent organs ${ }^{38-46}$.

\section{TREATMENT}

Therapeutical management varies with location and histological subtype. Therefore, mature mediastinal teratomas can be treated with complete surgical resection, through a median sternotomy or posterolateral thoracotomy. Sometimes, when complete surgical resection cannot be fulfilled without endangering surrounding vital structures, a partial resection can be performed on benign teratomas if this can relieve the compressive symptoms. Due to the fact that mature teratomas are relatively insensitive to chemotherapy and radiotherapy it is unclear if this additional treatment can offer any real benefit, and some authors recommend observation ${ }^{32,47}$.

In terms of management of immature teratomas, it is preferred to first do a four cycle of etoposide, ifosfamide, and cisplatin chemotherapy and then opt for a complete resection, if possible. Due to the rarity of this type of tumor it has not been established the benefits of chemotherapy and the optimal timing for surgery. Aray et al showed that long-term survival can be achieved using preoperative chemotherapy and aggressive surgical resection ${ }^{48}$.

Mediastinal seminoma and seminomas in general are highly sensitive to cisplatin-based chemotherapy and radiotherapy. The International Germ Cell Consensus Classification classifies men with mediastinal seminomas without evidence of non pulmonary organ metastases as good-risk GCTs and should be treated with three cycles of BEP or four cycles of etoposide and cisplatin (this regimen is preferred due to the lung toxicity of bleomycin). Patients who have metastases from a mediastinal seminoma should be treated with four cycles of bleomycin, etoposide, and cisplatin chemotherapy (BEP), and if bleomycin cannot be tolerated, four series of etoposide, ifosfamide, and cisplatin chemotherapy (VIP) chemotherapy should be administered ${ }^{35,49}$. Bokmeyer et al, in their study on 103 patients with extragonadal seminomas, in whom cisplatin-based chemotherapy was administered to $91 \%$ of cases, the remission rate with chemotherapy and post-chemotherapy resection of residual masses was $92 \%$, with a 5 -year survival rate of $88 \%$ (to be noted that in $75 \%$ of cases chemotherapy was used alone $)^{36}$. If the patient cannot benefit from chemotherapy, radiation therapy (RT) should be administered ( 35 to $50 \mathrm{~Gy}$ ), in an area that includes the mediastinum and bilateral supraclavicular fossae. RT can only be administered in the absence of a bulky and metastatic disease. Due to the cardio-vascular side-effects (coronary artery disease, valvular disease, diastolic dysfunction, and constrictive pericarditis) caution should be advised ${ }^{35}$. In cases of mediastinal seminomas, surgery is rarely needed. 
When a seminoma is very small and localized, a complete surgical resection can be performed, followed by adjuvant chemotherapy.

Residual masses larger than $3 \mathrm{~cm}$ should be evaluated with a positron emission tomography (PET scan) or an open biopsy, or should be closely observed, whereas those smaller than $3 \mathrm{~cm}$ should be closely observed or evaluated with a PET scan ${ }^{35}$.

Mediastinal NST are aggressive tumors and a multimodal approach is usually preferred. Usually, patients undergo 4 cycles of VIP chemotherapy (this is preferred due to the toxicity of bleomycin in BEP regimen). Four cycles of BEP are an alternative if bone marrow toxicity is a particular concern. In a series of 221 patients who underwent thoracic surgery for excision of mediastinal NSTs, 22 of 166 patients treated with BEP developed acute respiratory distress syndrome compared with 0 of 55 treated with VIP50. After neoadjuvant chemotherapy, most patients have residual masses and require complete surgical excision.

For retroperitoneal seminomas, the same cisplatin-based chemotherapy is the preferred approach. The regimen used is the same as for advanced testicular seminoma ${ }^{35}$. Initially, patients with retroperitoneal NST benefit from three or four cycles of cisplatin-based chemotherapy, after which they undergo surgery for any residual mass left. In a study on 227 patients with retroperitoneal NST of whom 98\% of cases were treated with chemotherapy, 101 cases undergo surgery for residual masses and the overall survival rate was $65 \%{ }^{36}$. In the retroperitoneum, pure teratomas are a rare encounter and are generally treated by surgical excision as a first line of treatment $t^{35}$.

\section{Prognosis}

Prognosis is strongly related to age, histotype, and anatomical location (direct effects of tumor on organs in certain locations). Histological type is a very important prognostic factor, as NSTs have a poorer long-time survival rate (45\%) compared with seminomatous GCTs $(90 \%)^{36}$. Regardless of age, mature teratomas behave in a benign manner, compared to immature teratomas, that have an aggressive behaviour in adults. Visceral metastases, increased serum beta-HCG, primary location into the medistinum and clinical and pathological staging are independent prognostic factors that corelate with a negative impact on overal survival rates ${ }^{20}$.

\section{Conclusions}

Extragonadal germ-cell tumors are an uncommon group of neoplasms, that, although they have similar components to their gonadal counterparts, are characterized by a total different biological manner, a poorer prognosis and a more aggressive behaviour, especially when they have NST components. EGCTs occur more frequent in the mediastinum and retroperitonem, but can be found in almost every structure along the midline of the body. Suspicion is raised by clinical presentation, serum markers and imaging studies, but the histopathological exam is the one that confirms the diagnosis. In terms of treatment, a multimodal approach is usually preferred, but it is heavily dictated by the histological type of the tumor, which also dictates the prognosis.

\section{Compliance with Ethics Requirements:}

„The authors declare no conflict of interest regarding this article"

\section{References}

1. Stang A, Trabert B, Wentzensen N, et al. Gonadal and extragonadal germ cell tumors in the United States, 1973-2007. Int J Androl. 2012;35(4):616-625.

2. Paradies G, Zullino F, Orofino A, Leggio S. Unusual presentation of sacrococcygeal teratomas and associated malformations in children: clinical experience and review of the literature. Ann Ital Chir. 2013;84:333-346.

3. Arora RS, Alston RD, Eden TO, Geraci M, Birch JM. Comparative incidence patterns and trends of gonadal and extragonadal germ cell tumors in England, 1979 to 2003. Cancer. 2012;118(17):4290-4297.

4. Hanna NH, Ulbright TM, Einhorn LH. Primary choriocarcinoma of the bladder with the detection of isochromosome 12p. J Urol. 2002;167(4):1781.

5. Wei Zheng, Lina Wang, Deyong Yang, et al. Primary extragonadal germ cell tumor: A case report on prostate seminoma. Oncol Lett. 2015 Oct; 10(4): 2323-2326.

6. Yao XD, Hong YP, Ye DW, Wang CF. Primary yolk sac tumor of seminal vesicle: a case report and literature review. World J Surg Oncol. 2012;10:189.

7. Euscher ED. Unusual presentations of gynecologic tumors: extragonadal yolk sac tumor of the vulva. Arch Pathol Lab Med. 2017;141(2):293-297.

8. Stolnicu S, Szekely E, Molnar C, et al. Mature and immature solid teratomas involving uterine corpus, cervix, and ovary. Int J Gynecol Pathol. 2017;36(3):222-227.

9. Kumar Y, Bhatia A, Kumar V, Vaiphei K. Intrarenal pure yolk sac tumor: an extremely rare entity. Int J Surg Pathol. 2007;15(2):204-206.

10. Heerema McKenney A, Harrison MR, Bratton B, Farrell J, Zaloudek C. Congenital teratoma: a clinicopathologic study of 22 fetal and neonatal tumors. Am J Surg Pathol. 2005;29(1):29-38.

11. Harms D, Schmidt D, Leuschner I. Abdominal, retroperitoneal and sacrococcygeal tumours of the newborn and the very young infant. Report from the Kiel Pediatric Tumour Registry. Eur J Pediatr. 1989;148(8):720-728.

12. Marchevsky AM, Wick MR. Pathology of the Mediastinum. Cambridge: Cambridge University Press; 2014.

13. Marina N, London WB, Frazier AL, et al. Prognostic factors in children with extragonadal malignant germ cell tumors: a pediatric intergroup study. J Clin Oncol 2006; 24: 2544. 
14. McKenney JK, Heerema-McKenney A, Rouse RV. Extragonadal germ cell tumors: a review with emphasis on pathologic features, clinical prognostic variables, and differential diagnostic considerations. Adv Anat Pathol 2007;14(2):69-92.

15. Glenn OA, Barkovich AJ. Intracranial germ cell tumors: a comprehensive review of proposed embryologic derivation. Pediatr Neurosurg 1996;24(5):242-51.

16. Sung MT, Maclennan GT, Lopez Beltran A, Zhang S, Montironi R, Cheng L. Primary mediastinal seminoma: a comprehensive assessment integrated with histology, immunohistochemistry, and fluorescence in situ hybridization for chromosome 12p abnormalities in 23 cases. Am J Surg Pathol. 2008;32(1):146-155.

17. Hasle H, Mellemgaard A, Nielsen J, Hansen J. Cancer incidence in men with Klinefelter syndrome. Br J Cancer. 1995;71(2):416-420.

18. Aguirre D, Nieto K, Lazos M, et al. Extragonadal germ cell tumors are often associated with Klinefelter syndrome. Hum Pathol 2006;37(4):477-480.

19. Williams LA, Pankratz N, Lane J, et al. Klinefelter syndrome in males with germ cell tumors: A report from the Children's Oncology Group. Cancer 2018;124:3900.

20. Bokemeyer C, Droz JP, Horwich A, et al. Extragonadal seminoma: an international multicenter analysis of prognostic factors and long-term treatment outcome. Cancer. 2001;91(7):1394-1401.

21. Ronchi A, Cozzolino I, Montella M, et al. Extragonadal germ cell tumors: Not just a matter of location. A review about clinical, molecular and pathological features. Cancer Med. 2019; doi: 10.1002/cam4.2195.

22. Looijenga LH, Stoop H, de Leeuw HP, et al. POU5F1 (OCT3/4) identifies cells with pluripotent potential in human germ cell tumors. Cancer Res. 2003;63(9):2244-2250.

23. Almstrup K, Hoei Hansen CE, Wirkner U, et al. Embryonic stem cell-like features of testicular carcinoma in situ revealed by genome-wide gene expression profiling. Cancer Res. 2004; 64: 4736-4743.

24. Korkola JE, Houldsworth J, Chadalavada RS, et al Down-regulation of stem cell genes, including those in a $200-\mathrm{kb}$ gene cluster at $12 \mathrm{p} 13.31$, is associated with in vivo differentiation of human male germ cell tumors. Cancer Res. 2006;66(2):820-827.

25. Gashaw I, Dushaj O, Behr R, et al. Novel germ cell markers characterize testicular seminoma and fetal testis. Mol Hum Reprod. 2007;13(10):721-727

26. Leroy X, Augusto D, Leteurtre E, Gosselin B. CD30 and CD117 (c-kit) used in combination are useful for distinguishing embryonal carcinoma from seminoma. J Histochem Cytochem. 2002;50(2):283-285.

27. Nogales FF, Quiñonez E, López-Marín L, Dulcey I, Preda O. A diagnostic immunohistochemical panel for yolk sac (primitive endodermal) tumors based on an immunohistochemical comparison with the human yolk sac. Histopathology. 2014; 65(1):51-59.

28. Xiao GQ, Priemer DS, Wei C, Aron M, Yang Q, Idrees MT. ZBTB16 is a sensitive and specific marker in detection of metastatic and extragonadal yolk sac tumor. Histopathology. 2017;71(4): 562-569.

29. Alvarado-Cabrero I, Hernández-Toriz N, Paner GP. Clinicopathologic analysis of choriocarcinoma as a pure or predominant component of germ cell tumor of the testis. Am J Surg Pathol. 2014; 38(1): 111-118.

30. Böhle A, Studer UE, Sonntag RW, Scheidegger JR. Primary or secondary extragonadal germ cell tumors? J Urol 1986;135(5):939-943.
31. Gilligan TD, Seidenfeld J, Basch EM, et al. American Society of Clinical Oncology clinical practice guideline on uses of serum tumor markers in adult males with germ cell tumors. J Clin Oncol. 2010; 28(20): 3388-3404.

32. Lewis BD, Hurt RD, Payne WS, et al. Benign teratomas of the mediastinum. J Thorac Cardiovasc Surg 1983;86(5):727-31.

33. Adebonojo SA, Nicola ML. Teratoid tumors of the mediastinum. Am Surg 1976; 42(5):361-5.

34. Gunes S, Varon J, Walsh G. Mediastinal teratoma presenting as massive hemoptysis in an adult. J Emerg Med 1997; 15(3):313-6.

35. Extragonadal germ cell tumors involving the mediastinum and retroperitoneum. https://www.uptodate.com/contents/ extragonadal-germ-cell-tumors-involving-the-mediastinum-and-retroperitoneum (accessed October 25, 2019)

36. Bokemeyer C, Nichols CR, Droz JP, et al. Extragonadal germ cell tumors of the mediastinum and retroperitoneum: results from an international analysis. J Clin Oncol 2002; 20:1864-73.

37. Funt SA, Patil S, Feldman DR, et al. Impact of teratoma on the cumulative incidence of disease-related death in patients with advanced germ cell tumors. J Clin Oncol 2019; 37(26):2329-37.

38. Bratu O, Mischianu D, Spinu D, Barla R, Hoara P, Constantinoiu S. Paraneoplastic syndrome in primitive retroperitoneal tumours. Chirurgia (Bucur) 2013;108(1):26-31.

39. Constantinoiu S, Barla R, Iosif C, et al. Difficulties in diagnosis and surgical treatment of a giant retroperitoneal lipoma. Chirurgia (Bucur) 2009;104(3):363-367.

40. Marcu RD, Spinu AD, Socea B, et al. Castleman`s disease clinical, histological and therapeutic features. Rev Chim (Bucharest) 2018;69(4):823-830.

41. Bratu OG, Marcu RD, Socea B, et al. Immunohistochemistry particularities of retroperitoneal tumors. Rev Chim (Bucharest) 2018;69(7):1813-1816.

42. Bratu OG, Cherciu AI, Bumbu A, et al. Retroperitoneal tumors - treatment and prognosis of tumour recurrence. Rev Chim (Bucharest) 2019;70(1):190-194.

43. Marcu RD, Ionita-Radu F, Iorga LD, ey al. Vascular involvement in primary retroperitoneal tumors. Rev Chim (Bucharest) 2019;70(2):445-448.

44. Socea LI, Visan DC, Barbuceanu SF, Apostol TV, Bratu OG, Socea B. The antioxidant activity of some acylhydrazones with dibenzo[a,d][7]annulene moiety. Rev Chim (Bucharest) 2018;69(4):795-797.

45. Draghici T, Negreanu L, Bratu OG, et al. Liver abnormalities in patients with heart failure. Arch Balk Med Union 2018;53(1):76-81

46. Socea B, Nica A, Ovidiu Bratu OG, et al. Incidental finding of a sigmoid intussusception associated with rectal prolapse-a case report. Arch Balk Med Union 2018;53(1):143-146.

47. Feo CF, Chironi G, Porcu A, et al. Videothoracoscopic removal of a mediastinal teratoma. Am Surg 1997;63(5):459-61.

48. Arai K, Ohta S, Suzuki M, Suzuki H. Primary immature mediastinal teratoma in adulthood. Eur J Surg Oncol 1997; 23(1):64-67.

49. Samuels ML, Johnson DE, Holoye PY, Lanzotti VJ. Large-dose bleomycin therapy and pulmonary toxicity. A possible role of prior radiotherapy. JAMA 1976; 235(11):1117-20.

50. Ranganath P, Kesler KA, Einhorn LH. Perioperative morbidity and mortality associated with bleomycin in primary mediastinal non seminomatous germ cell tumor. J Clin Oncol 2016;34(36):4445-46. 